\title{
Comparative study of vaginal delivery and caesarean section in antepartum eclampsia at tertiary care hospital
}

\author{
Priti Kumari*, Sipra Singh, Salma Khatun, Shashikar
}

Department of Obstetrics and Gynecology, KMC, Katihar, Bihar, India

Received: 11 December 2016

Accepted: 17 December 2016

\author{
*Correspondence: \\ Dr. Priti Kumari, \\ E-mail: pritigupta.shashi@gmail.com
}

Copyright: () the author(s), publisher and licensee Medip Academy. This is an open-access article distributed under the terms of the Creative Commons Attribution Non-Commercial License, which permits unrestricted non-commercial use, distribution, and reproduction in any medium, provided the original work is properly cited.

\begin{abstract}
Background: Eclampsia is characterized by the sudden onset of generalized tonic clonic seizures. Eclampsia is usually preceded by a history of the pre-eclampsia but rarely arises in a woman with minimally increased blood pressure and no proteinuria. Eclampsia most commonly occurs in the third trimester, though rarely eclampsia may occur before $20 \mathrm{wks}$ in molar or multiple pregnancy. The aim of the study was to compare maternal and fetal outcome in antepartum eclampsia when terminated by vaginal delivery and caesarean section.

Methods: 50 women with eclampsia attending emergency department OBG department of Katihar Medical College, Katihar were collected from Feb 2015 to Sep 2016. Depending upon the mode of delivery, they were divided into two groups, CD group where caesarean section was performed and VD group where vaginal delivery was performed.

Results: Of the 50 cases, caesarean section was done in $40 \%$ of the cases, while vaginal delivery was carried was carried in 60\%.Maternal complications in CD group was 35\% and $80 \%$ in VD group $(\mathrm{p}<0.001)$. The incidence of live births, still birth and neonatal death was $85 \%, 15 \%, 0 \%$ in CD group and 60\%, 40\%, 10\% in VD group. The corrected perinatal mortality was $50 \%$.

Conclusions: Timely caesarean section reduces maternal and perinatal mortality and improves their outcome in antepartum eclampsia.
\end{abstract}

Keywords: Antepartum eclampsia, Caesarean section, Vaginal delivery

\section{INTRODUCTION}

The term eclampsia is derived from a Greek word "like a flash of lightening". 1

The onset of convulsion in a woman with pre-eclampsia that cannot be attributed to other causes is termed eclampsia. $^{2}$

The hospital incidence of eclampsia in India ranges from 1 to 500 to 1 in 30 . It is more common in primigravidae (75\%), five times more common in twins than in singleton pregnancies and occurs between the $36^{\text {th }}$ week and term in more than $50 \% .^{1}$ Incidence of eclampsia in India approx. $1.5 \%$.
The incidence of eclampsia is $0.3-0.9 \%$ in western countries. It has a maternal mortality rate of 0.5 to $10 \% .^{3}$ Globally, pre-eclampsia and eclampsia account for 10$15 \%$ of maternal death. ${ }^{4}$ Most of the over half a million maternal deaths that occur annually are in the developing countries like india. ${ }^{5}$ Eclampsia is characterized by the sudden onset of generalised tonic clonic seizures. Eclampsia occurs antepartum 38-43\%, intrapartum in 15$20 \%$ and post-partum in $11-44 \%$ (Fernando arias $4^{\text {th }}$ edition).Eclampsia most commonly occurs in the third trimester, though rarely eclampsia may occur before 20 weeks in molar or multiple pregnancy. Late postpartum eclampsia is diagnosed when eclamptic seizures develop beyond $48 \mathrm{hrs}$ within 4 weeks postpartum. 
Eclampsia is essentially a disease of the poor and of the primigravidae, a product of ignorance and neglect. Ideally, it is a preventable disease or almost so. The exact leading pathophysiology of eclampsia is still not understood yet now. It may be due to cerebral vasospasm or cerebral edema and explanation for the onset of seizures in women with normal perfusion pressure is that in this case. Seizures are the result of an abnormal autoregulatory response consisting of exaggerated vasoconstriction and ischaemic changes with rupture of the vascular endothelium (Fernando arias4th edition).Eclampsia is associated with elevated maternal and fetal morbidity and mortality. Case fatality rate in eclampsia as reported in UK is $1.8 \%$ and another $35 \%$ have some morbidity. Major maternal complications include placental abruption (7-10\%), DIC (7-11\%), HELLP syndrome (9.7-20\%), acute renal failure (5-9\%), pulmonary edema (3-5\%), cerebral haemorrhage $(2-5 \%)$.

Perinatal mortality occurs in about $5-12 \%$ of the cases. The most common substantial and correlates strongly with preterm birth, abruption placentae, FGR (Fernando arias4th edition). Convulsion during pregnancy that is unrelated to pre-eclampsia need to be distinguished from eclampsia. Such disorders include seizure disorders as well as brain tumour, aneurysm of the brain, and medication or drug-related seizures. Usually the presence of the signs of severe pre-eclampsia precedes and accompanies eclampsia, facilitating the diagnosis.

Regarding for prevention and management of eclampsia includes early detection of severe pre-eclampsia and use of magnesium sulphate to prevent eclampsia. Early management of eclampsia may reduce the severity of maternal and perinatal complications. Regarding treatment of the eclampsia, main goal of the treatment is to stop and prevent convulsion, to control the blood pressure, to deliver the baby as promptly as possible, and to monitor closely for the onset of multi-organ failure. Magnesium sulphate acts as a neuroprotective and anticonvulsant drug.

As we do not have adequate facilities for intrapartum management, caesarean section is preferred in many cases, particularly when the fetus is alive, considering the fact that patients and the foetuses may not tolerate the stress of labour.

\section{METHODS}

In the present prospective randomized study, 50 women with eclampsia attending the emergency department of obstetrics and gynaecology at Katihar medical college and hospital were collected between February 2015 to September 2016.The inclusion criteria were antepartum eclampsia, primi and multi gravida, duration of gestation $>24$ weeks. The exclusion criteria were-Cases with previous history of epilepsy, eclampsia of multiple pregnancy, known cause of renal disease.
Patients with eclampsia who were admitted during the study period were randomly divided in to two groups, (1) V.D group vaginal delivery group (control group) (2) C.D group caesarean delivery group (study group). All women examined at the time of admission and a detailed history was taken. Investigation were sent for complete blood count, urine analysis, blood grouping, Rh-typing, Renal function test, liver function test and coagulation profile.

Medical management was advised as per the management protocol of the study. The participants were induced, allowed to undergo spontaneous labour or underwent caesarean delivery depending on the obstetric indications and patients general condition.

\section{RESULTS}

Of the 50 cases, caesarean section was done in $40 \%$ of the cases, while vaginal delivery was carried out in $60 \%$ of the cases. Maternal complication were seen in $35 \%$ of the cases in C.D group and $80 \%$ of the cases in V.D group ( $<<0.001$ highly significant) (Table 2). Maternal deaths occurred in none of the cases in the C.D group and $10 \%$ of the cases in the V.D group. The incidence of the live birth, still birth and neonatal death was $85 \%, 15 \%$, $0 \%$ in C.D group and 60\%, 40\%, 10\% in V.D group. The corrected perinatal mortality rate in V.D group was $50 \%$. Apgar score $<5$ at 1 minute was seen $17.6 \%$ in C.D group and $73 \%$ in V.D group (Table1).

Table 1: Perinatal outcome among vaginal delivery and caesarean section $(n=50)$.

\begin{tabular}{|c|c|c|c|c|}
\hline \multirow{2}{*}{$\begin{array}{l}\text { Perinatal } \\
\text { outcome }\end{array}$} & \multicolumn{2}{|c|}{ V.D. group } & \multicolumn{2}{|c|}{ C.D. group } \\
\hline & $\begin{array}{l}\text { No. of } \\
\text { cases }\end{array}$ & Percentage & $\begin{array}{l}\text { No. of } \\
\text { cases }\end{array}$ & Percentage \\
\hline $\begin{array}{l}\text { Apgar }<5 \\
\text { at } 1 \\
\text { minute }\end{array}$ & $\begin{array}{l}14 \text { out } \\
\text { of } 18\end{array}$ & $73 \%$ & $\begin{array}{l}3 \text { out } \\
\text { of } 17\end{array}$ & $17.6 \%$ \\
\hline $\begin{array}{l}\text { Need for } \\
\text { NICU } \\
\text { stay }\end{array}$ & $\begin{array}{l}15 \text { out } \\
\text { of } 18\end{array}$ & $83.3 \%$ & $\begin{array}{l}8 \text { out } \\
\text { of } 17\end{array}$ & $47.6 \%$ \\
\hline $\begin{array}{l}\text { Live } \\
\text { birth }\end{array}$ & 18 & $60 \%$ & 17 & $85 \%$ \\
\hline Still birth & 12 & $40 \%$ & 3 & $15 \%$ \\
\hline $\begin{array}{l}\text { Neonatal } \\
\text { death }\end{array}$ & 3 & $10 \%$ & 0 & $0 \%$ \\
\hline
\end{tabular}

\section{DISCUSSION}

Eclampsia a devasting complication is still associated with a great deal of maternal and fetal loss. Control of convulsion and management of hypertension are two important of the eclampsia. There is conclusive evidence that magnesium sulphate (mgso4) is the best available drug for management of eclampsia.7. Incidence of eclampsia in our hospital was $1.25 \%$. 
Table 2: Maternal complications after vaginal delivery group and caesarean group.

\begin{tabular}{|c|c|c|c|c|}
\hline \multirow[t]{2}{*}{ Complication } & \multicolumn{2}{|l|}{$\begin{array}{l}\text { C.D. } \\
\text { group }\end{array}$} & \multicolumn{2}{|l|}{$\begin{array}{l}\text { V.D. } \\
\text { group }\end{array}$} \\
\hline & $\begin{array}{l}\text { No. } \\
\text { of } \\
\text { cases }\end{array}$ & Percentage & $\begin{array}{l}\text { No. } \\
\text { of } \\
\text { cases }\end{array}$ & Percentage \\
\hline $\begin{array}{l}\text { Postpartum } \\
\text { hemorrhage }\end{array}$ & $\begin{array}{l}1 \text { out } \\
\text { of } 20\end{array}$ & $5 \%$ & $\begin{array}{l}5 \text { out } \\
\text { of } 30\end{array}$ & $16.6 \%$ \\
\hline $\begin{array}{l}\text { Abruption } \\
\text { placenta }\end{array}$ & - & - & $\begin{array}{l}1 \text { out } \\
\text { of } 30\end{array}$ & $3.33 \%$ \\
\hline $\begin{array}{l}\text { Acute renal } \\
\text { failure }\end{array}$ & - & - & $\begin{array}{l}1 \text { out } \\
\text { of } 30\end{array}$ & $3.33 \%$ \\
\hline $\begin{array}{l}\text { Cerebral } \\
\text { hemorrhage }\end{array}$ & & & $\begin{array}{l}2 \text { out } \\
\text { of } 30\end{array}$ & $6.66 \%$ \\
\hline $\begin{array}{l}\text { Pulmonary } \\
\text { edema }\end{array}$ & - & - & $\begin{array}{l}1 \text { out } \\
\text { of } 30\end{array}$ & $3.33 \%$ \\
\hline Fever & $\begin{array}{l}3 \text { out } \\
\text { of } 20\end{array}$ & $15 \%$ & $\begin{array}{l}8 \text { out } \\
\text { of } 30\end{array}$ & $26.66 \%$ \\
\hline $\begin{array}{l}\text { Transient } \\
\text { blindness }\end{array}$ & - & - & $\begin{array}{l}1 \text { out } \\
\text { of } 30\end{array}$ & $3.33 \%$ \\
\hline $\begin{array}{l}\text { Urinary tract } \\
\text { infection }\end{array}$ & $\begin{array}{l}3 \text { out } \\
\text { of } 20\end{array}$ & $15 \%$ & $\begin{array}{l}2 \text { out } \\
\text { of } 30\end{array}$ & $6.66 \%$ \\
\hline $\begin{array}{l}\text { Postpartum } \\
\text { fits }\end{array}$ & - & - & $\begin{array}{l}1 \text { out } \\
\text { of } 30\end{array}$ & $3.33 \%$ \\
\hline $\begin{array}{l}\text { Retained } \\
\text { placenta }\end{array}$ & - & - & $\begin{array}{l}1 \text { out } \\
\text { of } 30\end{array}$ & $3.33 \%$ \\
\hline $\begin{array}{l}\text { Electrolyte } \\
\text { imbalance }\end{array}$ & - & - & $\begin{array}{l}1 \text { out } \\
\text { of } 30\end{array}$ & $3.33 \%$ \\
\hline Total & $\begin{array}{l}7 \text { out } \\
\text { of } 20\end{array}$ & & $\begin{array}{l}24 \\
\text { out } \\
\text { of } 30\end{array}$ & \\
\hline
\end{tabular}

$\mathrm{P}<0.001$ : Highly significant

In the present series, 50 patients with antepartum eclampsia were studied from February 2015 to September 2016 by dividing in to two groups;

1. V.D group, where vaginal delivery was carried out.

2. C.D group, caesarean section was performed.

Incidence of caesarean section was $40 \%$ and that of vaginal delivery was $60 \%$ in my study but study of Mario Lopezllera found incidence of caesarean section 40.4\%.In both groups; the highest incidence of eclampsia was found in the age group 20-25 years. This was comparable in studies of Hakerwadi, Vinita Banshal, Dr. G. Mahalakshmi. In both groups, $80 \%$ of the cases belonged to low socioeconomic status. The highest gestational age incidence was found between 36 to 40 weeks in both groups of my study. Most studies found the incidence of eclampsia <37 weeks. According of study of Probhakaretal, Chaudhary and Sunithaetal also found highest number of eclamptic patients in gestational age $>37$ weeks. ${ }^{8,9}$ Most of the patients were admitted in a compromised after compromised state after throwing of convulsions at home. However, almost $80 \%$ of cases in both groups had thrown $<5$ convulsions. Most of them were conscious but irritable on admission.

The chances of successful induction of the labour are low in primigravidae with an unfavourable cervix at $<34$ weeks of gestation. Bishops score was unfavourable $80 \%$ of cases in the C.D group and $36.66 \%$ in V.D group. Indication of caesarean section in my study was cervical factor $50 \%$, fetal distress $25 \%$, abnormal labour $25 \%$. According Mondal RN series ${ }^{10}, 41$ out of 62 cases caesarean section was a deliberate decision with the sole purpose of shortening the exposure to delivery.

In our present study, both vaginal delivery and caesarean section group were compared on important characteristics such as maternal and perinatal morbidity and mortality. Regarding fetal outcome, Apgar score at 1 minute $<5$ in $18 \%$ cases in C.D group and $73.3 \%$ in V.D group, most of the babies born vaginally being asphyxiated. Even NICU admission rates showed differences- $46 \%$ in the C.D group and $83.3 \%$ in the V.D group. Incidence of live births, still birth, neonatal deaths was $85 \%, 15 \%, 0 \%$ in C.D group but $60 \%, 40 \%, 10 \%$ in V.D group. There was striking difference in the incidence of live birth and still birth in both groups could be due to increased rate of IUGR, LBW, preterm babies in the V.D group. Study of Dandekar LM showed 10\% PNM in C.D group and 40\% PNM in V.D group. ${ }^{11}$ PNM increased in proportion to increase in the number of convulsions, similar study was observed by Mundle $\mathrm{S}$ and Swain. ${ }^{12,13}$ PNM also increased proportionately as the first convulsion-delivery interval increased in both the groups.

Perinatal outcome was found to be definitely better in cases where caesarean section was done in comparison to those who delivered vaginally.

\section{Regarding maternal outcome}

Maternal complications were encountered in $35 \%$ of the cases in the C.D. group and $80 \%$ of the cases in the V.D. group. The complications were postpartum hemorrhage was $16.6 \%$, abruption placenta $3.33 \%$, acute renal failure $3.33 \%$ cerebral hemorrhage $6.66 \%$, pulmonary edema $3.33 \%$, fever $26.6 \%$, transient blindness $3.33 \%$, UTI $6.66 \%$, postpartum fits $3.33 \%$, electrolyte imbalance $3.33 \%$ in V.D. group but very few complication was seen in C.D. group. Patient was died due to intracranial haemorrhage, acute renal failure in V.D. group and no death was seen in C.D. group. Incidence of maternal death occurred in $10 \%$ of the cases in the V.D. group while there were no maternal deaths in the C.D. group. According to menon ${ }^{14}$ observed that maternal mortality increased with increase in the first convulsion delivery interval. Sheuly begum series 2013 incidence of maternal mortality $6 \%$ in V.D. and $0 \%$ in C.D. group. ${ }^{15-20}$

Maternal complication was encountered in $80 \%$ in V.D. group and $35 \%$ of cases in C.D. group. 


\section{CONCLUSION}

Early termination of pregnancy by caesarean section reduces maternal and perinatal mortality improves maternal outcome by reducing complications and also improves perinatal outcome with better one minute Apgar scores and reduced NICU stay. Both maternal and perinatal outcome can be improved by taking early decision for caesarean section when admission cervix is unfavourable or delivery is not anticipated within 6hrs.In the severe antepartum eclamptic with a closed uneffaced cervix and unengaged presenting parts, it might give better results if conservative treatment is supplemented by timely caesarean section instead of withholding it.

Funding: No funding sources

Conflict of interest: None declared

Ethical approval: The study was approved by the Institutional Ethics Committee

\section{REFERENCES}

1. Dutta DC. Textbook of Obstetrics. 8th Ed. Calcutta. New Central Book Agency Pvt. Ltd.; 1998: 234-254.

2. Williams Obstetrics. 24th Ed., McGraw Hill Co. Inc., 2005:761-808.

3. Knight M. Eclampsia in the United Kingdom 2005. BJOG. 2007;14(9):1072-8.

4. Turner IA. Diagnosis and Treatment of preeclampsia: an update. International Journal of women's Health. 2016; pp. 327-337.

5. World health organization. Reduction of Maternal mortality. A Joint WHO/UNFDA/UNICEF AND WORLD BANK statement Geneva WHO: 1999.

6. Fernando Arias' Practical Guide to High-Risk Pregnancy and Delivery, 4th Edition. pp. 424-427.

7. Eclampsia Working Group: Eclampsia in Bangladesh, a review and a guide line. Bangladesh J Obstet Gynecol. 1996;12:1-25.

8. Prabhakar G, Shinde MA, Jadhav CA. clinical study of eclampsia patient at Dr. V.M. government
Medical College Solapur, India. JOSR. 2015;13(7):10-6.

9. Choudhary P. Eclampsia: A hospital based Retrospective study. Kathmandu University Medical Journal. 2003;J(4):237-41.

10. Bhattacharya PK, Purkayastha, Basu M. Robinsanath M. caesarean section in eclampsia still a dilemma. J Obstet and Gynecol. 1992;42(1):51-5.

11. Dandekar LM. Eclampsia: perinatal hospital experience. JI Obstet and Gynecol. 1993;43(1):42-4.

12. Smite J. Perinatal mortality in eclampsia. J Obstet Gynecol. 1989;39:792-4.

13. Mario Lopez - Llera, Rubio Linares and Hernandez Horta. Maternal mortality rates in eclampsia. Amj of Obsatetic and Gynecol. 1983:146-307.

14. Menon K. Cesarean section in eclampsia. J Obstet Gynecol. British EMP. 1961: 68-461.

15. Hakerwadi AV, Taner CE, Garden AC, Ozelbaykal V. Prevalence, management and outcome in eclampsia. Lancet. 1996;348(9024):364-9.

16. Habeebullah S, Agarwal A, Swain S, Arora R. Impact of mode of delivery on maternal mortality in eclampsia. JIMA. 1997;95(40).

17. Sheehan HL, Lynch JB. Cerebral lesion in: Pathology of toxaemia of pregnancy. Baltimore. Williams and Wikins, 1973.

18. Abdullah AR, Nalliah S. Eclampsia in Kelantan. West Aft Med. 1990;9(3):157-63.

19. Mitraand S, Das K. Management of eclampsia. J of obstet and Gynec Brit Emp. 1957:64:74-8.

20. Sibai BM, Ramadan MK. Maternal morbidity and mortality in 442 pregnancies with HELLP syndrome. Am J Obstet Gynecol. 1991;174:454.

Cite this article as: Kumari $\mathrm{P}$, Singh $\mathrm{S}$, Khatun $\mathrm{S}$, Shashikar. Comparative study of vaginal delivery and caesarean section in antepartum eclampsia at tertiary care hospital. Int J Reprod Contracept Obstet Gynecol 2017;6:457-60. 